\title{
Mobile Learning in Suzuki Violin Lessons: A Study of QR Code Game
}

\author{
Gülşah Sever \\ Correspondence: Gülşah Sever, Music Education Department, Faculty of Education, Gazi University, Ankara, Turkey.
}

Received: September 19, 2019

doi:10.11114/jets.v7i10S.4532

\author{
Accepted: October 20, $2019 \quad$ Online Published: October 24, 2019 \\ URL: https://doi.org/10.11114/jets.v7i10S.4532
}

\begin{abstract}
This was a qualitative research that aimed to identify the opinions of Suzuki violin students on a QR Code game designed within the scope of mobile learning. Clues about the technical and musical aspects of the pieces in the $1^{\text {st }}$ book of Suzuki method, and entertaining tasks were stored in QR codes. The content analysis of observations, student interviews, student attitude forms, and expert opinions were conducted on Maxqda 12 qualitative analysis software. This provided information on the effect of the QR Code game on repeats, its compliance with technology, and opinions on white and yellow cards. Findings of the study revealed that the QR Code game allowed the students to repeat the pieces in Suzuki repertoire on different cognitive, affective, and psychomotor levels over and over. In the study, the students had a positive attitude towards the QR Code game and an active participation in the process that led to a positive and cheerful learning environment.
\end{abstract}

Keywords: mobile learning, QR code, music education, Suzuki method, violin

\section{Introduction}

Mobile learning is defined as a type of learning conducted with the help of mobile devices such as tablets, laptops, handheld computers, and smartphones, that may occur within or outside class activities (Kukulska-Hulme \& Traxler, 2005). Besides this, mobile learning also handles issues pertaining to the promotion of well-intended educational goals through effective education and information management (Vosloo, 2012). The increase in number of people owning mobile devices in all countries, including groups with socioeconomic and cultural disadvantages (ITU, 2011), and their permanent position within the countries' national education policies (Legislative Council, 2013; Fatih Project, 2012) implies that accelerated into the research process of these technologies is required so as to find effective ways to utilize them in education.

QR Code is a freely-available easy to use mobile applications technology that offers a wide range of products. QR code can be used by teachers while designing different activities for their students. Because these codes have been utilized for educational purposes before; such as for history (Chen and Choi, 2010), chemistry (Bonifacio, 2012), and language teaching (Liu, Tan, and Chu, 2010), this proves that they can increase the interest, motivation and achievements of students (Kukulska-Hulme\& Traxler, 2005; Chen et al. 2008; Liaw et al. 2010). Utilization of QR Codes in music and instrumental education is a relatively new subject. Further studies pertaining to the use and effects of QR Codes in music and instrumental education are required. Keeping this in mind, this study seeks to ascertain the attitude and opinions of students and teachers regarding the use of QR Codes in Suzuki Violin courses.

\section{Literature Review}

\subsection{Mobile Learning}

Learning takes place in every aspect of life. Thanks to their easy access and portability, mobile technologies are increasingly used in every learning environment. Traxler (2010) mentioned the educational aspects of mobile learning and emphasized that the use mobile technologies in education can be individually or socially based supporting all kinds of pedagogical options. Several studies (Reychav \& Wu, 2014; Chang, Chen, \& Hsu, 2011; Hsu \& Ho, 2012) suggest that mobile learning models are beneficial and usable during learning-teaching processes. The main advantages of using mobile devices include providing student-oriented teaching and learning contexts where student-learning depends on their active involvement, and teachers are generally seen as facilitators (O'Bannon and Thomas, 2015; Khan et al., 2016). One of the push effects that make this technology a potential teaching-learning tool is the increasing usage of mobile devices among the younger generation (Zaranis et al., 2013; Ismail et al., 2016). Mobile learning is currently used in many fields, especially in science and technology. In this study, mobile learning is used in music and instrumental education. 


\subsection{Mobile Learning and Music Education}

Like other fields of education, mobile learning has started to take its place in music education. Leong (2011) proposed that interactive applications and activities ought to be developed for such a prosperous experience where students can lead the process individually. This would include listening to different pieces, improving listening skills, and recording performances at home. Music teachers also utilize industrial and social networking applications such as Soundcloud, Youtube, and Spotify in their classes for micro-teaching, performance improvement, and evaluation purposes in addition to sound and video recording programs, which come as default in mobile devices. Apart from these general applications, there are also special software designed exclusively for music education. Among these applications are the ones for babies and children (Music School for Toddlers, Baby Mozart, Musical Me), for solfeggio and music theory training [GNU Solfege, Practica- Musica (Ng\&Nesi, 2008), i-Maestro], for instrument learning [Digital Violin Tutor (Yin, Wang\&Hsu, 2015), Piano Maestro], for music history (Let's go to the Opera), for note writing [Finale, Sibelius (Roblyer, 2006)], and for composing (Hyperscore, Toc and Roll). Chen (2015) concluded that the Auralbook application is an effective tool for teaching audial skills such as rhythmic clapping at beginner level and improving intermediate singing skills and also raises the users' learning motivation. Paula-Ruiz et al. (2016) studied SAMI application and revealed that children who practiced with this application showed a positively significant improvement, particularly in hearing and creativity games, when compared to those learning through colored bells. Magalhaes et al. (2018), found that Ritornello application enhanced students' interest, participation and learning motivation in music and art courses. Chen et al. (2018) used mobile learning for the purpose of facilitating the follow-up and arrangement of study routines of students and suggested that the application was effective in creating accurate study routines and thereby improving their musical performances. Dunbar (2019) stated that mobile applications can be used to evaluate music performance.

Findings obtained from studies conducted on participants of different age groups for different purposes showed that these applications were useful in musical learning despite their various limitations. With more than $80 \%$ of educational mobile applications in the digital stores of iTunes and Google Play appealing to children, parents and educators are faced with a multitude of decisions regarding the choice of the right application. Teachers and parents need to make critical and informed decisions when selecting applications for use (Papadakis\& Kalogiannakis, 2017). The educational value and appropriateness of the app content can be challenging to ascertain (Yusop and Razak, 2013). Furthermore, certain applications do not function in different operating systems and require in-application purchase making them rather difficult to use the in classroom. Additionally, the current applications are limited to the options provided by the software. Only music teachers are actually knowledgeable on the requirements of the respective field. It is difficult for teachers to design such applications, while performing their regular professional roles. Improvement of these applications require an exchange of interdisciplinary knowledge and projects. Therefore, utilization of QR Codes in music education is believed to be a huge opportunity to make these applications adaptable to different purposes.

\subsection{QR Codes in Learning and Teaching}

QR Codes (abbreviated from Quick Response codes) were first designed for the automotive industry to provide codes for vehicles to easily track their production process (Denso-wave, 2013). QR codes provide a shortcut between the related product and the system connection the product is linked to, with the help of the data encoded in it. This shortcut can direct the user to a website, a default text, a picture, a map, a video, a phone number etc. Development of QR Codes are rather easy, practical and at no cost.

The usage of QR codes in the education sector can play an important role in the process of empowering technology in educational activities (Law and So, 2010). Recently, QR codes have been used at all education levels, from primary to higher education in learning courses in a variety of subject areas (Susono and Shimomura, 2006; Ramsden, 2008; Ceipidor et al., 2009; Crompton, 2013; Lai et al., 2013; Lai and Hwang, 2014). Çataloğlu and Ateşkan (2014) mention that QR codes can be used in two different ways;to direct a student to a web-based platform to access online applications, and to enable a student access information without an internet connection. Studies have shown that when online learning sources are used in combination with the published works (e.g. books, written class notes), they enhance the student's interest and motivation towards the subject and increase learning success (Kukulska-Hulme and Traxler, 2005; Chen et al. 2008; Liaw et al. 2010). Studies such as learning history through QR codes (Chen and Choi, 2010), processing of the periodic table where each chemical element is explained with a QR code (Bonifacio, 2012), environmental education (Kalogiannakis\& Papadakis, 2017), geocaching with QR codes (Sharma, 2013), and QR code-aided foreign language education (Liu, Tan, and Chu, 2010) illustrate the benefits of QR codes in different fields. This study focuses on the use of QR codes in music education.

\subsection{Use of QR Codes in Music Education}

As in other fields of education, QR codes enable the creation of interesting activities in music and instrument education 
courses, too. Wardrobe (2013) state that QR codes faciliate the preparation of QR-coded posters providing shortcut to the videos, performances, web sites, or residential maps of artists the students admire. QR codes also allow access to performance videos of musicians or students. It was established that with a $\mathrm{QR}$ code assigned to a piece written using a note writing program, students can be directed to video courses where they can learn how to write these notes. Also, the addition of QR codes into given pieces in a group study or orchestra class, will direct students to websites where they can access information about the composers, performers and its history. Miracle (2015) suggested that QR code technology can be used for the purposes of listening, watching, confirming an answer, visiting a web page, and preparing a class bulletin. Kelleher (2015) specified that QR codes can be used to provide a wider range of interactive sources for students in order to encourage them to listen more and learn independently. He prepared QR codes connected to YouTube videos to enhance students' inadequate information about orchestra and hanged these codes on office doors, classroom walls, and corridors. He observed that students enjoyed scanning these codes and built up the deficits in their information on orchestra in a short time. Kelleher also used QR codes for feedback and peer assessment purposes and found that it was possible to identify A, B, C level performances with the help of QR codes that directed the students to student performances uploaded to YouTube anonymously and comments placed on YouTube by students.

QR codes have been used for a long time in the industry; however, QR research is still brand new in music education. Although user experiences about the use of QR codes in music education are available on the Internet and various blogs, there is limited information based on published research studies. Palazon and Giraldes (2018) used the flipped learning model and proved that using QR-coded videos to play instrument established a suitable system and provided immediate responses to students during indoor and outdoor class activities. In order to analyze the effectiveness of QR codes in instrument education, it is crucial to work with students taught using the same method and approach or work in a controlled classroom to demonstrate systematic improvement. The Suzuki method is a repertoire of developing from easy to difficult, depending on the technical and musical development line in which all students follow the same study plan and learn a common repertoire. Therefore, in this study, QR codes were designed for Suzuki violin students sharing the same learning culture and repertoire.

\subsection{Suzuki Method}

Shinichi Suzuki (1898-1998) was Japanese violin teacher and founder of the internationally acclaimed Talent education, which is also known as Mother Tongue Method approach. He published his first study in 1978, in which he observed how babies learned their mother tongues. He then adapted it into instrument education. Fundamental to the Suzuki philosophy of education is the belief in 'nurture' over 'nature' - that is, that we are all 'children of our environment' (Suzuki [1969] 1981). Although the Suzuki philosophy contains many fundamental principles, in this study, we will only focus on the following principles:

Every child can learn: Just as children are able to acquire the language(s) spoken around them by their parents and caregivers, Suzuki believed that everyone was capable of developing high levels of ability in any area of learning, provided they were given the right conditions: 'Every child can be educated; it is only a matter of the method of education. Anyone can train himself [or herself]; it is only a question of using the right kind of effort' (Suzuki, 2010).

Encouragement: Similar to learning a language, a child's effort to learn how to use an instrument should be met with sincere praise and encouragement. Each child learns at his/her own rate, building on small steps so that each step can be mastered. Children are also encouraged to support each other's efforts, fostering an attitude of generosity and cooperation. Based on this principle, studies and games are conducted in learning courses with no consideration for competition and scores.

Group based instruction: Group music experiences allow students to perform common Suzuki repertoires together while also aurally absorbing new repertoires performed by other more advanced players in the group (Reuning-Hummel et al. 2016). Students are explicitly taught to offer support and encouragement to one another in group lessons (Suzuki [1969] 1981). Suzuki students are taught both in individual lessons and in weekly or bi-weekly group lessons (Guerriero et al. 2016). In the final group lessons, teachers can also plan masterclasses where students listen to each other.

Listening: Like the immersive nature of learning a first language, Suzuki emphasized the importance of having children immersed in the sounds of quality music from a very young age (Thibeault 2018). The best examples of the repertoire of classical music and the sensitive listening of Suzuki pieces are included the 'listening' scope.

Graded repertoire: 'Suzuki repertoire' is published alongside methods written for each instrument, and the sound recordings of the pieces in them. Each instrument has a standard program and follows a ranked repertoire. Suzuki trainers remain adherent to this repertoire and the order of pieces because every piece prepares the performer for the next one and serves as a constructive block that supports forming a carefully designed technique (Sak-Brody, 2016).

Repetition: Another important aspect of Suzuki method is that the musical pieces used for training are constantly 
repeated. Suzuki defined this approach as "polishing or lightening the piece" (Suzuki, 2010). Students are given weekly repeats during training sessions, to practice the previously learned pieces. This improves and perfects their technique and musicality, encourages them to try new musical elements, and eases the application of a newly learned technique on previous pieces. Teachers can allocate more time to these repeats during group lessons. Since children who play different pieces sit together during group sessions, this mechanism of 'repeat' becomes spontaneous. However, during the individual classes the focus is on an individual piece and technique, and the repeats of previous pieces are assigned as homework.

Should a need for a new material emerged, the retrospective and prospective practice of different techniques and musical activities would be used instead of repeating the pieces as they are during the individual and group sessions. This diversifies the cognitive, affective, and psychomotor knowledge of students through the game approach; is convenient for the teacher yet still attract students' attention and motivates them, and encourages their curiosity about the use of technology. To meet this need, a QR code game which included entertaining tasks and clues about the remarkable aspects of the pieces was designed by the researcher. Within this context, the aim of the study is to identify students' opinions on the QR code game. In light of this information, the study attempts to answer the following questions:

- Is QR code technology compatible with Suzuki learning?

- What is the effect of QR code game on the repetitions?

- What are the students' attitudes and opinions regarding the white guess cards in the QR code game?

- What are the students' attitude and opinions regarding the yellow fun cards in QR Code?

\section{Method}

\subsection{Research Design}

The study was based on the case study model, is a qualitative research method, to allow for the collection holistic and comprehensive data about the QR code game and the effects of the clues and tasks provided in white and yellow cards on students, and learning opportunities offered by this QR code game that was being applied to the field of violin education for the first time. According to Creswell (2007), a case study is a qualitative research approach where the researcher analyzes one or more cases that remained limited in the course of time, through collecting data from multiple sources (observations, interviews, visual-audial data, documents, reports) in order to identify cases and dependent themes. Case studies may include close analysis of humans, subjects, issues, or programs. Experiences of students in a school, the issue of cheating in another school etc. are known to be cases that are unique and special (Hays, 2004). Among case study designs, the holistic single-case study was utilized in this research. According to this design, there is only one unit of analysis (an individual, an institution etc.). This approach can be used in researching excessive, controversial, or authentic cases, as well as the ones never studied before, to confirm or disprove a well-formulated theory (Baxter\&Jack, 2008). Applications regarding the use of QR code technology in instrument education have just emerged in literature. Single-case study design was used in this research due to the need for a deeper knowledge.

\subsection{Study Group - Sample}

Criterion sampling method was used in the study. Students of Suzuki method were purposefully selected, due to practicing the same repertoire, following the same curriculum, and taking group classes together. The QR code game was applied to 4 students for a total of 15 times. As per ethical rules, the study was based on voluntary participation and consent was obtained prior to participation. To anonymize the participants, all participants were given codes in the study. Characteristics of the students are provided below:

Table 1. Attributes of participants

\begin{tabular}{lcccc}
\hline & S1 & S2 & S3 & S4 \\
\hline Level of Violin & Suzuki 1 & Suzuki 1 & Suzuki 1 & Suzuki 1 \\
\hline Last Piece Practiced & Andantino & Etude & Minuet 2 & Gavotte \\
\hline Participation in Individual Sessions & Once a week & Once a week & Once a week & Once a week \\
\hline Participation in Group Sessions & 4 times in a month & 4 times in a month & $\begin{array}{c}\text { Once in a } \\
\text { month }\end{array}$ & $\begin{array}{c}\text { Once in a } \\
\text { month }\end{array}$ \\
\hline Owns a personal movile device & No & No & Yes & Yes \\
\hline Sex & F & M & F & F \\
\hline Age & 9 & 12 & 14 & 15 \\
\hline
\end{tabular}




\subsection{Researcher's Role}

In the study, the researcher served as a participating observant and applicator. In the application of QR codes, the researcher took the role of referee as a violin teacher, where she explained the game and the rules when necessary.

\subsection{Creating the QR Code Game}

Cognitive task analysis method was used while creating the QR code game. To do so, pieces in the first book of Suzuki were analyzed in terms of technique and musical tasks, and clues were prepared to identify related pieces. The analysis was conducted by the researcher initially, and later in consulation with three Suzuki violin teachers. Clues which were found insufficient, unnecessary, or misleading were excluded by the teachers.

To prepare the yellow entertaining cards, the researcher created a list of 22 items that included technical, musical, psychomotor, cognitive and affective items and shared it with Suzuki teachers. They tested the tasks by playing them and tasks which were found inappropriate were eliminated leaving 14 items. For the content tests of both the clues and entertaining cards, the expressions and phrases were shared with a language specialist before taking its final form. According to the techniques of the piece, the white cards contained 4 to 6 clues.

The expressions prepared for the guessing game- white cards and yellow- entertaining cards were encoded on the free online QR code generation site (https://www.the-qrcode-generator.com/). Code clues which were downloaded in PNG format were tabulated and printed.

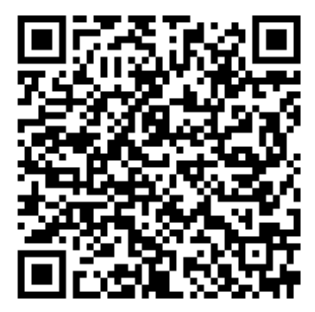

Figure 1. An example of the White (clue) cards

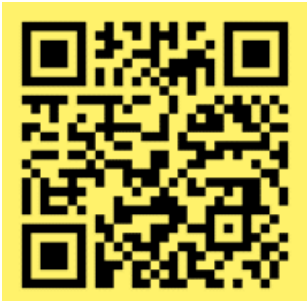

Figure 2. An example of the yellow (entertaining) cards

\subsection{How to Play QR Code Game}

Preparation: White and yellow cards were printed out. A QR code scanner application was downloaded to at least one of the mobile devices in the class.

Application: The application followed the steps below:

1. Students picked one of the $\mathrm{QR}$ codes printed on white paper.

2. The application was started and the QR code scanned using a mobile devices.

3. The students then tried to identify the piece with the least number of clues possible.

4. They then played the piece on the violin.

5. If they accomplished playing the piece with a limited number of mistakes, they got to pick a yellow entertaining card. If they had difficulties in playing the piece, the teacher provided a short practice lesson so that the piece could be learnt or improved.

6. Students who played the piece without mistakes or with a limited number of mistakes could pick one or more yellow entertaining cards and learn how to play the piece by means of scanning the code (while sticking out tongue or standing on one foot etc.).

7. The students then replayed the piece while fulfilling the entertaining task. 
8. Depending on the time allocated to the course or the activity, more white and yellow entertaining cards were selected and the activity repeated.

In group lessons, one of the students chose a card while his or her friends tried to guess the piece silently. The student then played the piece alone. The task from the yellow card was done together with the entire class.

\subsection{Data Collection}

Descriptive and confirmatory data collecting tools were both utilized in this research to collect elaborate opinions on different perspectives on the use of QR codes. Observatory notes and student interviews were consulted for descriptive tools; while student attitude form and expert opinions were consulted for confirmatory tools.

Observations: This included real-time observations during applications and re-observation of recorded applications for purpose.

Student Interviews: Students were asked for their opinions at the end of the every QR code game application. These interviews consisted of short answers given by students within the natural course of the practice.

Student Attitude Form: A five-point likert type attitude form consisting of 10 items was prepared by the researcher. The statements about the QR code game were shared with a linguist and a pedagogue and necessary corrections were made.

Expert Opinions: Three Suzuki violin experts were consulted for their opinions while analyzing the accuracy of the clues identified for the QR code game by the researcher, as well as the appropriateness of tasks written in the cards. For the linguistic compliance of the expressions in the cards and attitude form, a linguist and a pedagogue were consulted for their opinions.

\subsection{Validity and Reliability}

Case studies allow for elaborate investigation into the analysis unit (case). Therefore, data triangulation is a substantial characteristic of this research design in order to provide thorough and contextual explanations. In the study, the knowledge of different shareholders in the QR code game application were collected as course records, student and expert opinions. Following the coding conducted during the content analysis for reliability, themes and tables of codes were shared with a field specialist to check the data. The data were rearranged and finalized after consulting an expert.

\subsection{Data Analysis}

The study was based on qualitative data. Data obtained from observations and interviews were decoded and transferred to Maxquda 12 qualitative analysis software. Pre-structured case system was utilized while conducting the content analysis. During the organization of field notes, certain quantitative data on the QR Code game application were also obtained. Frequencies pertaining to how many times the application was conducted, and how many times the yellow cards were practiced were summarized. The supportive data obtained from the student attitude form were presented in a table by taking the average and percentage values through basic statistical procedures. While the average and percentage values were calculated in the survey, the scores given by the students were calculated separately for each expression.

\section{Results}

\subsection{Technology Compliance}

Te students were familiar with the QR code technology. When they saw the codes, S2 and S4 said they were familiar with the code as they used them in their school courses, but it was the first time they saw it in a music course. S1 and S3, on the other hand, were seeing these "shapes" (codes) for the first time. After a brief explanation about the functioning of these codes, they easily comprehended how to open a QR code scanner from a phone and adapted to the application quickly.

There was no challenges experienced by students when scanning QR codes. In one of the courses, S4 realized the code could not be scanned while the phone was in an upright position, but then rotated the phone and easily scanned the code from a broader angle. In another course, S2 and S1 could not scan a code located in the middle of a page. They teamed up to cover the other codes with their hands and were able to scan it. The students gave positive responses about the technology on the attitude scale provided after the study. The responses given by the students in the attitude survey and their percentages are provided in the table below: 
Table 2. Student attitude for QR codes

\begin{tabular}{|c|c|c|c|}
\hline & \multirow[t]{2}{*}{ Statements } & \multicolumn{2}{|c|}{ Responses } \\
\hline & & Av. & $\%$ \\
\hline 1 & It is rather easy to scan the $\mathrm{QR}$ codes & 4.75 & 95 \\
\hline 2 & It is fun to scan the $\mathrm{QR}$ codes on the phone & 4.5 & 90 \\
\hline 3 & $\begin{array}{l}\text { I started seeing QR codes in daily life, } \\
\text { thanks to QR code game }\end{array}$ & 4.25 & 85 \\
\hline 4 & It is rather difficult to scan the QR codes & 0.25 & 6 \\
\hline
\end{tabular}

According to the table, it was easy and fun for the students to scan the QR codes. They stated that they gained an awareness for QR codes in their daily lives, thanks to the game. These data correspond to the observation results, too. S4 expressed that s/he downloaded a QR code scanner to the phone at the end of the study, and now started to scan QR codes on posters or bus stops.

\subsection{Impact of the QR Code Game on Repeats}

One of the main purposes of the QR code game is to increase purposeful repeats, a vital scope of the Suzuki method, which makes it more entertaining for students. Since students picked one card after the other during the game, the number of repeats of the pieces were random. When the identical pieces were played over and over, previously played codes were withdrawn from the deck. More cards were chosen according to the time allocated to the course and the wishes of the students. Application frequencies of the white cards are as follows:

Table 3. Repeat numbers of white cards

\begin{tabular}{llc}
\hline & White Cards & Frequency \\
\hline 1 & Song of the Wind & 4 \\
2 & Long Long Ago & 4 \\
3 & Allegro & 4 \\
4 & Perpetual Motion & 4 \\
5 & Allegretto & 3 \\
6 & Lightly Row & 2 \\
7 & Go Tell Aunt Rhody & 2 \\
8 & O come little children & 2 \\
9 & Andantino & 2 \\
10 & May song & 1 \\
& Total & 28 \\
\hline
\end{tabular}

As seen in the table, pieces were practiced total of 28 times during 15 applications. This frequency corresponds to almost twice the number of applications. The data indicates that the QR code game had a considerable effect on the repitition of previous pieces. During the application, students got to pick one yellow card, and the number of repeats were multiplied based on the tasks in each yellow card. Within the context of the study, the students were allowed to pick one yellow card in 13 out of 15 applications by playing the pieces with no mistakes or very few mistakes. Tasks and frequencies in the yellow cards are as follows: 
Table 4. Repeat numbers of yellow chards

\begin{tabular}{ll|c}
\hline \multicolumn{1}{c}{ Yellow cards } & Frequency \\
\hline 1 & Play lightly (piano) & 4 \\
2 & Play while sticking your tongue out. & 2 \\
3 & In which tone the piece was written? Play the scale. & 2 \\
4 & Play Pizzicato. & 2 \\
5 & Play while walking around & 2 \\
6 & Play sadly. & 2 \\
7 & Play with your eyes shut. & 2 \\
8 & You play the bows while your friend is playing the left hand. & 2 \\
9 & What is the story of the piece? & 2 \\
10 & Have your friends play the piece. & 1 \\
11 & Play forte. & 1 \\
12 & Play slowly. & 1 \\
13 & Play fast. & 1 \\
14 & Write the starting note of the piece. & 26 \\
\hline
\end{tabular}

As seen in the table, a total of 26 yellow card tasks were practiced in 13 applications where students got to pick a yellow card. The numbers above were obtained by having the students select a yellow card depending on the time period allocated to the application. Each application contained an average of two yellow cards.

\subsection{Students' Attitude and Opinions on White Cards}

In QR code game, students were initially asked to identify the piece by using the cognitive clues that indicated the characteristics of the piece. Some of the clues provided in the cards were "I am the piece that starts by up bow for the first time", "I start with a A5". In the first application, certain students had some difficulties in identifying the piece from the clues in white cards due to the novel approach to thinking about the pieces. They expressed that they did not focus on the clues but then got used to them and found it easy to identify them. Even though S4 and S1 could identify the notes, melodies, and technical features of the pieces correctly, they had difficulties in remembering their names. However, towards the end of the application, they started to associate the names with the techniques and remembered most of them correctly.

The difficulty levels of the clues provided played a role in identifying the pieces. The clue "I start with a A5" in the piece Allegro allowed the students to easily identify the piece. With the help of the QR codes, students became more eager to scan the codes, talk and apply the technical aspects of the piece. Like in every game, there were a couple of contradictions in this game too, which drove the players to guess. To increase the opportunities during which the players could guess, other supporting clues that would cause a selection factor between the pieces with the same technical features for instance, the clue "I have skipping notes", were applied to some other pieces as well. This left S2 undecided. Nevertheless, this was considered useful in providing an opportunity to talk about the technical features of different pieces in class.

In the attitude survey, students were given statements about the white cards and asked to grade the statements based on their opinions. The statements and students' responses are provided below: 
Table 2. Student attitude for guessing white cards

\begin{tabular}{lllc}
\hline \multicolumn{1}{c}{ Statements } & \multicolumn{2}{c}{ Responses } \\
\cline { 3 - 3 } & & Av. & $\%$ \\
1 & $\begin{array}{l}\text { I can easily guess the piece thanks to the } \\
\text { clues in QR codes }\end{array}$ & 4.5 & 90 \\
2 & $\begin{array}{l}\text { I worry about encountering with a piece I do } \\
\text { not know while selecting a QR code }\end{array}$ & 1.25 & 31.25 \\
\hline
\end{tabular}

As seen in the table, most students stated that they could easily guess the piece. But still, they also said they were worried about encountering a piece they knew nothing about. Since the QR code game was based on repeating the previously practiced pieces, unknown pieces were not included in the course. However, should a long time have elapsed since a piece was practiced, it is possible that the student may have forgotten the piece. It was observed that students concerned about encountering a piece they were not familiar with did not participate in the courses regularly; whereas those who were not concerned about encountering an unknown piece regularly participated in the weekly group course. Therfore the level of concern was directly linked to frequency of participation in the course.

\subsection{Students' Attitude and Opinions on Yellow Cards}

In the game, once the student identified the piece picked from the white cards, and played the piece with no mistakes or very few mistakes, s/he got to pick a yellow card. The tasks in yellow cards aimed to psychologically and physically relieve the students, have them feel different musical expressions, and build a bridge between their emotions and music. The yellow card that asked the students to "play while sticking your tongue out" was the task that students enjoyed the most. This specific task allowed students to play the difficult parts of the piece correctly and in a relaxed manner.

The response to the task "Play while walking around" was different for each student. For instance, S1 found that it hindered the playing. However, S2 and S3 expressed their appreciation for this task. Playing and walking around helped to control the tempo in the piece because the momentum in the tempo was harmonized with the pace of walking. Another yellow card the students liked was "becoming bow friends". In this task, the violin was played by two students where one of them played the left-hand notes of the piece, while the other one played the bows. This required the students to start the piece concurrently and coordinate to play in turns. It also allowed the students to focus on specific points since the left- and right-hand techniques of musical piece's differed from each other. Initially, the students were only able to obtain scratchy sounds. Subsequently, they were able to fixed the distortion by identifying a solution together. Students were fond of this task since it made playing more entertaining and included teamwork and active learning processes.

Another yellow card the students enjoyed was "What is your impression of the piece? Tell us its story". This was in one of the yellow cards for the piece Perpetual Motion. S2 told the story of the piece by saying "It feels like soldiers are pacing for their morning exercise". Indeed, Perpetual Motion stands for pacing in lexical sense. Bowings of the piece require the constant repetition of the same movement. The same yellow card task was picked in another class, for the piece Long Long Ago. Here, the students wrote two stories, one of them being "Long long ago, in 1918, there was a war", and the other one "In the past, many years ago, there were women sewing dresses and helping each other". Both stories were detailed during the application, and the piece was practiced in a way that would reflect this feeling. In the following interviews, students said they found the card entertaining and useful, and added "we have never written a story for music before, I liked the card as it was different" and "the music becomes more meaningful when you make up a story about it".

Table 3. Student attitude for yellow chards

Statements

\begin{tabular}{cc}
\multicolumn{2}{c}{ Responses } \\
\hline Av. & $\%$ \\
4.5 & 90 \\
3 & 75 \\
2.25 & 56.25
\end{tabular}

3 I have difficulties in performing the task in yellow cards, while I am playing the violin 
As seen in the table, students believed the tasks in yellow cards made the lesson more entertaining. However, they had difficulties in performing the tasks in yellow cards that contained novel musical and psychomotor skills. For instance, the task "play while walking around" required the student to play the piece on a level ground. If there were parts in the piece where the student was uncertain, it equally became difficult to walk around.

In the QR code game, yellow cards were designed to add entertainment and vary the musical challenge. These challenges were congruent with the level of students' skills. The students reported having difficulties half the time. This turned out to be a proportion where students did not give up, despite the difficulty.

\section{Discussion}

In this study, QR codes were utilized within the context of a game prepared to have students guess the technical and musical aspects of musical pieces in the Suzuki method repertoire, in order to improve their performances through entertaining tasks with repetitions. Within the framework of the principles of 'Every child can learn' and 'Encouragement' in the Suzuki method, the concept of play was designed for sharing and collective learning and not for competion and scores.

The first research question addressed the competency of the students in the QR code technology. Since it was not possible to identify clues without having read the codes, technology compliance was prerequisite to playing the game. There were no problems experienced in scanning the QR codes. Since participating students were aged between 9 and 15 years, they could be part of the technological generation, who are called digital natives. Heide and Stilborne (2000) expressed that the technological revolution has created a totally different generation with different perspectives, who grew up with different sources of multidimensional and interactive media. Within this context, integration of digital platforms and mobile devices (tablets, smartphones etc.) into education is vital. Leon (2011) suggested in The Horizon Report that musical education has strong bonds with global economy and digital age; and made certain predictions about the future of the field. To integrate these technologies into music education, engineering programming and musical knowledge must be blended. While researches and companies are currently working on these mobile applications, music teachers would require more practical solutions based on their own needs. Based on this perspective, the QR code technologies can be regarded as a preliminary solution since they are easy to prepare and use, low cost, and allow the teachers to use them for different purposes.

The second research question was about the effect of QR code game on repetitions. With the help of white cards, students had the chance to study about the technical and musical aspects of the pieces; while the entertaining tasks in yellow cards creatively increased the number of repetitions. In Suzuki method, repeating the previously learnt pieces plays a vital role. In this way, a sustainable development is feasible especially in group sessions where students from different levels study together. This helps the advanced level students to revise previous pieces and practice them; while providing the opportunity for the beginners to practice technical and musical aspects of the pieces together. Bransford and Scwartz (1999) define offering conceptual knowledge by inventing a game that includes any higher level skill (as opposed to constantly emphasizing the subjects to be learned in the related field and the information to be remembered) as "preparation for future learnings". Within this context, QR code game creates opportunities holistic learning in both individual and group lessons.

The third research question was on the student's opinions and attitudes towards white clue cards. Using white cards, students were asked to identify the piece based on clues about the bowing, left hand techniques and melody structure. In the first couple of applications, students had some difficulties in identifying the piece but then got used to this new approach. According to Gee (2007), educational games with progressive levels of difficulty play a vital role in developing skills such as critical thinking, problem solving, innovation, creativity, social relationships, and effective use of technology. Using white cards, students had the chance to discuss cognitive processes regarding violin playing. The students were slightly worried about picking a card with a clue they did not know about; nevertheless, such a hesitation is in the nature of the game. Kiili et al. (2012) asserted that students start with easy tasks in educational video games and they keep going as long as the difficulty level within their limits. However, in the event that the difficulty level exceeds their psychological limits, their potential underperformance may cause a sense of concern. The students were observed to reflect similar attitude when they were faced with an unknown clue.

The last study question was on student's opinions and attitudes on yellow fun cards. After having guessed the pieces in white cards, students selected one of the yellow cards where they got to perform different musical tasks. The aim of yellow cards was to improve the performance of the students by means of assigning them to a task that challenged their musical or psychomotor skills. Half of the students expressed difficulty in performing the tasks written in yellow cards. However, they did not give up despite the difficulty they experienced. In the flow theory, Csikszentmihalyi (1990) mentioned an optimal performance is accomplished in not-so-challenging or non-deterrent levels of difficulty. Based on the students' willingness to continue, the QR code game can be suggested to embody a certain level of difficulty enabling this state of flow. 
In this study, only clues in the form of sentences were added into the QR codes. In future studies, codes may contain directions that lead students to videos and internet sources about the composer or how to play the piece, etc. The content can be designed for use both during the lesson $\&$ at home or during learning and practice conditions. In future studies, the effects of QR code game on attention, performance and motivation can be also studied. Data on the opinions and attitudes of students on the QR code game obtained through interviews and observations were limited to a short application period; therefore, the impact of QR code game on the student performance and attitude can be assessed in a long-term study.

\section{References}

Baxter, P., \& Jack, S. (2008). Qualitative case study methodology: study design and implementation for novice researchers. The Qualitative Report, 13(4), 544-559. Retrieved from https://nsuworks.nova.edu/tqr/vol13/iss4/2

Bonifacio, V. (2012). QR-coded audio periodic table of the elements: a mobile-learning tool. Journal of Chemical Education, 89, 552-554. https://doi.org/10.1021/ed200541e

Bransford, J. D., \& Schwartz, D. L. (1999). Rethinking transfer: A simple proposal with multiple implications. In A. Iran-Nejad \& P. D. Pearson (Eds.), Review of research in education, 24(pp. 61-101). Washington, DC: American Educational Research Association. https://doi.org/10.2307/1167267

Çataloğlu, E., \& Ateşkan, A. (2014). Use of qr codes in education with examples. Elementary Education Online, 13(1), 5-14. http://ilkogretim-online.org.tr/index.php/io/article/view/2100/1936

Ceipidor, U. B., Medaglia, C. M., Perrone, A., De Marsico, M., \& Di Romano, G. (2009). A museum mobile game for children using QR-codes, Proceedings of the 8th International Conference on Interaction Design and Children, ACM, New York, pp.282-283. https://doi.org/10.1145/1551788.1551857

Chang, C. S., Chen, T. S., \& Hsu, W. H. (2011). The study on integrating webquest with mobile learning for environmental education. Computers \& Education, 57(1), 1228-1239. https://doi.org/10.1016/j.compedu.2010.12.005

Chen, C. W. (2015). Mobile learning: using application auralbook to learn aural skills. International Journal of Music Education, 33, 244-259. https://doi.org/10.1177/0255761414533308

Chen, G. D., Chang, C. K., \& Wang, C. Y. (2008). Ubiquitous Learning Website: Scaffold Learners by Mobile Devices with Information aware Technologies. Computers \& Education, 50(1), 77-90. https://doi.org/10.1016/j.compedu.2006.03.004

Chen, X., \& Choi, J. (2010). Designing online collaborative location-aware platform for history learning. Journal of Educational Technology Development and Exchange, 3(1), 13-26. https://doi.org/10.18785/jetde.0301.02

Chen, Y., Klaus, A., Liang, Y., \& Zhang, C. (2018). Improving music practice with a mobile learning smartphone application. International Association for Development of the Information Society, Paper presented at the International Association for Development of the Information Society (IADIS) International Conference on Mobile Learning (14th, Lisbon, Portugal, Apr 14-16, 2018)

Creswell, J. W. (2007). Qualitative inquiry \& research design: Choosing among five approaches USA: SAGE Publications

Crompton, H. (2013). A historical overview of mobile learning: toward learner-centered education, in Berge, Z.L. and Muilenburg, L.Y. (Eds): Handbook of Mobile Learning, Routledge, Florence, KY, pp.3-14.

Csikszentmihalyi, M. (1990). Flow: the psychology of optimal experience. Journal of Leisure Research, 24(1), 93-94. https://doi.org/10.1080/00222216.1992.11969876

Denso-wave, (2013). High capacity encoding of data. [Online: http://www.qrcode.com/en/about/], Access Date: $10^{\text {th }}$ April 2017. http://www.denso-wave.com/qrcode/aboutqr-e.html

Dunbar, L. (2019). When Responses Cannot Be Written Down: Video Submission Possibilities in the Music Classroom. General Music Today, 32(3), 29-30. https://doi.org/10.1177/1048371319832880

Fatih Project: http://fatihprojesi.meb.gov.tr/en/index.html (accessed 10th of February 2019)

Finfgeld-Connett, D. (2010). Generalizability and trasferabilty of meta-synthesis research findings. Journal of Advanced Nursing, 66(2), 246-254. https://doi.org/10.1111/j.1365-2648.2009.05250.x

Gee, J. P. (2007). What Video Games Have to Teach Us about Learning and Literacy, 2nd ed. Palgrave McMillan, 8788.

George, M., \& Apter, A. J. (2004). Gaining insight into patients' beliefs using qualitative research methodologies. Curr 
Opin Allergy Clin Immunol, 4(3), 185-189. https://doi.org/10.1097/00130832-200406000-00008

Guerriero, E., Mitchell, N., Einarson, K., Hendricks, K., \& D’Ercole, P. (2016). IRSTE part four: The joys and benefits of Suzuki group class. American Suzuki Journal, $44(3), \quad 8$. https://www.uwsp.edu/suzuki/Documents/IRSTE/14th/44-3\%20ASJ\%20Part\%204.pdf. Accessed 12 April 2019

Guetterman, T. (2015). Descriptions of sampling practices within five approaches to qualitative research in education and the health sciences. Educational Psychology Papers and Publications, 263. https://digitalcommons.unl.edu/edpsychpapers/263

Hays, P. A. (2004). Case study research. In K. deMarrais \& S. D. Lapan (Eds.), Foundations for research: Methods of inquiry in education and the social sciences (pp. 217-234). Mahwah, NJ: Lawrence Erlbaum Associates.

Heide, A., \& Stilborne, L. (2000). Guia do Professor para a Internet - Completo e fácil. Porto Alegre - Brasil, Artmed Editora.

Hsu, C. C., \& Ho, C. C. (2012). The design and implementation of a competency-based intelligent mobile learning system. Expert Systems with Apllications. https://doi.org/10.1016/j.eswa.2012.01.130

Ismail, I., Azizan, S. N., \& Gunasegaran, T. (2016). Mobile learning in malaysian universities: are students ready?. International Journal of Interactive Mobile Technologies, 10(3). https://doi.org/10.3991/ijim.v10i3.5316

ITU, International Telecommunication Union (2011). The World in 2011: ICT Facts and Figures. Geneva, Switzerland, Author. http://www.itu.int/ITUD/ict/facts/2011/material/ICTFactsFigures2011.pdf

Kalogiannakis, M., \& Papadakis, S. (2017). Combining mobile technologies in environmental education: a Greek case study. Int. J. Mobile Learning and Organisation, 11(2), 2017. https://doi.org/10.1504/IJMLO.2017.10005249

Kelleher, J. (2015). Qr Codes in Music. Retrieved from http://www.teacherandmusician.com/2015/07/guest-post-qr-codes-in-music.html/ (accessed July 6, 2015)

Khan, A. I., Al-khanjari Z., \& Sarrab, M. (2016). Crowd sourced testing through end users for Mobile Learning application in the context of Bring Your Own Device. 2016 IEEE 7th Annual Information Technology, Electronics and Mobile Communication Conference (IEMCON), Vancouver, BC, 2016, pp. 1-6. https://doi.org/10.1109/IEMCON.2016.7746256

Kiili, K., Freitas, S., Arnab, S., \& Lainema, T. (2012). The design principles for flow experience in educational games. Procedia Computer Science, 15, 78-91. https://doi.org/10.1016/j.procs.2012.10.060

Kukulska-Hulme, A., \& Traxler, J. (Eds.), (2005). Mobile Learning: A Handbook for Educators and Trainers. London: Routledge

Lai, C. L., \& Hwang, G. J. (2014). 'Effects of mobile learning time on students' conception of collaboration, communication, complex problem-solving, meta-cognitive awareness and creativity', International Journal of Mobile Learning and Organisation, 8(3-4), 276-291. https://doi.org/10.1504/IJMLO.2014.067029

Lai, H. C., Chang, C. Y., Wen-Shiane, L., Fan, Y. L., \& Wu, Y. T. (2013). The implementation of mobile learning in outdoor education: application of QR codes', British Journal of Educational Technology, 44(2), E57-E62. https://doi.org/10.1111/j.1467-8535.2012.01343.x

Law, C., \& So, S. (2010). QR codes in education, Journal of Educational Technology Development and Exchange, 3(1), 85-100. https://doi.org/10.18785/jetde.0301.07

Legislative Council of Hong Kong (2013). LCQ20: E-textbook Market Development Scheme. Retreived January 5, 2017, from http://www.info.gov.hk/gia/general/ 201310/30/P201310300378.htm

Leong. S. (2011). Navigating the emerging futures in music education. Journal of Music, Technology and Education, 4(2 \& 3), 233-244. https://doi.org/10.1386/jmte.4.2-3.233_1

Liaw, S. S., Hatala, M., \& Huang, H. M. (2010). Investigating Acceptance toward mobile learning to assist individual knowledge management: based on activity theory approach. Computers \& Education, 54(2), 446-454. https://doi.org/10.1016/j.compedu.2009.08.029

Liu, T. Y., Tan, T. H., \& Chu, Y. L. (2010). QR code and augmented reality-supported mobile english learning system. Mobile Multimedia Processing: Fundamentals, Methods, and Applications, 5960, 37-52. https://doi.org/10.1007/978-3-642-12349-8_3

Magalhaes, D. S., Monteiro, J. J. G., Carvalho, J. A., Magalhaes, W. A. M., \& Monteiro, C. C. (2018). Mobile application and technology as a motivational support to the learning process of artlmusic. Revista Sitio Novo, 2 January- June-18 Instutio Federal do Tocantins. 
Miles, M. B., \& Huberman, A. M. (1994). Qualitative Data Analysis: An Expanded Sourcebook. Newbury Park; London: Sage

Miracle, A. (2015). How to use qr codes in classroom. Retrieved from https://www.mrsmiraclesmusicroom.com/2015/04/how-to-use-qr-codes-in-classroom.html (accessed July 6, 2015)

$\mathrm{Ng}, \mathrm{K}$., \& Nesing, P. (2008). I-maestro framework and interactive multimedia tools for technology-enhanced learning and teaching for music. In $4^{\text {th }}$ International Conference on Automated Solutions for Cross Media Content and Multi-Channel Distribution, AXMEDIS'08, Italy. https://doi.org/10.1109/AXMEDIS.2008.41

O’Bannon, B. W., \& Thomas, K. M. (2015). Mobile phones in the classroom: preservice teachers answer the call', Computers \& Education. https://doi.org/10.1016/j.compedu.2015.02.010

Palazón, J., \& Giráldez, A. (2018). QR codes for instrumental performance in the music classroom. International Journal of Music Education, 36(3), 447-459. https://doi.org/10.1177/0255761418771992

Papadakis, S., \& Kalogiannakis, M. (2017). Mobile educational applications for children: what educators and parents need to know, Int. J. Mobile Learning and Organisation, 11(3), 256-277. https://doi.org/10.1504/IJMLO.2017.085338

Paule-Ruiz, M. P., Álvarez-García, V., Pérez- Pérez, J. R., Álvarez-Sierra, M., \& Trespalacios-Menéndez, F. (2016). Music learning in preschool with mobile devices, Behaviour \& Information Technology. https://doi.org/10.1080/0144929X.2016.1198421

Ramsden, A. (2008). The Use of QR Codes in Education: A Getting Started Guide for Academics, Working Paper (Unpublished), University of Bath, UK. Available online at: http://opus.bath.ac.uk/11408/

Reuning-Hummel, C., Meyer, A., \& Rowland, G. (2016). Powerful learning experiences and Suzuki music teachers, International Journal of Education \& the Arts, 17:36, http://www.ijea.org/v17n36/. Accessed 1 June 2018.

Reychav, I., \& Wu, D. (2014). Exploring Mobile tablet training for road safety: a uses and gratifications perspective, Computers \& Education. https://doi.org/10.1016/j.compedu.2013.09.005

Robertson, C., \& Green, T. (2012). Scanning the potential for using qr codes in the classroom. Techtrends: Linking Research \& Practice to Improve Learning, 56(2), 11-12. https://doi.org/10.1007/s11528-012-0558-4

Roblyer, M. D. (2006). Integrating Educational Technology into Teaching. Pearson Prentice Hall Publications.

Sak, B. Z. (2016). "Suzuki yetenek eğitimi" felsefesine kısa bir bakış. Anadolu Üniversitesi Sanat \& Tasarım Dergisi, 6 , 79-79. https://doi.org/10.20488/www-std-anadolu-edu-tr.291235

Sharma, V. (2013). Qr codes in education- a study on innovative approach in classroom teaching. IOSR Journal of Research\& Method in Education (IOSR-JRME), 3(1), 62-70. https://doi.org/10.9790/7388-0316270

Susono, H., \& Shimomura, T. (2006). Using mobile phones and qr codes for formative class assessment. In A. MéndezVilas, J.A.A., Solano Martín, M., González, J.M. González (Eds.), Current developments in technology-assisted education, 2. Badajoz, Spain, pp. 1006-1010.

Suzuki, S. ([1969] 1981). Ability development frome age zero (trans. M. L. Nagata), Miami, FL: Summy-Birchard.

Suzuki, S. (2010). Sevgiyle eğitmek (nurtured by love). Porte Müzik Eğitim Yayınları Porte Music Education Publishing, Turkey

Thibeault, M. (2018). Learning with sound recordings: A history of Suzuki's mediated pedagogy, Journal of Research in Music Education, 66(1), 6-30. https://doi.org/10.1177/0022429418756879

Traxler, J. (2010). Will student devices deliver innovation, inclusion, and transformation. Journal of the Research Center for Educational Technology, 6.

Vosloo, S. (2012). Mobile learning and policies: key issues to consider. Paris, UNESCO. (UNESCO Working Paper Series on Mobile Learning.) http://unesdoc.unesco.org/images/0021/002176/217638E.pdf

Wardrobe, K. (2013). Qr codes in music education. Retrieved from http://soundhouse.org.au/packages/qrcodes-in-music-education/

Yin, J., Wang, Y., \& Hsu, D. (2005). Digital violin tutor: an integrated system for beginning violin learners. Proceedings of the $13^{\text {th }}$ ACM International Conference on Multimedia, MM 2005: 976-985 ScholarBank@ Nus Repository. https://doi.org/10.1145/1101149.1101353

Yusop, F. D., \& Razak, R. A. (2013). Mobile educational apps for children: towards development of i-CARES framework, Annual International Conference on Management and Technology in Knowledge, Service, Tourism \& 
Hospitality, Jakarta, Indonesia. https://doi.org/10.1201/b16700-12

Zaranis, N., Kalogiannakis, M., \& Papadakis, S. (2013). Using mobile devices for teaching realistic mathematics in kindergarten education, Creative Education, 4, 1-10. https://doi.org/10.4236/ce.2013.47A1001

\section{Copyrights}

Copyright for this article is retained by the author(s), with first publication rights granted to the journal.

This is an open-access article distributed under the terms and conditions of the Creative Commons Attribution license which permits unrestricted use, distribution, and reproduction in any medium, provided the original work is properly cited. 